\title{
CRÓNICA DE UNA MOVILIZACIÓN ANUNCIADA: TODOSSOMOSAYOTZINAPA ${ }^{1}$
}

\section{CHRONICLE OF AN ANNOUNCED MOBILIZATION: TODOSSOMOSAYOTZINAPA}

\author{
Anna María Fernández Poncela*
}

RESUMEN

Este texto se centra en analizar los logros del movimiento por Ayotzinapa desde la mirada social. Tras los hechos en la ciudad de Iguala en el Estado de Guerrero en el año 2014, donde 6 personas resultaron asesinadas y 43 estudiantes desaparecidos, se levantó un movimiento en todo México. Desde la academia se suele estudiar los orígenes y las causas de los movimientos, pero en este caso se pretende analizar sus consecuencias y logros. Para esto, se realizaron entrevistas a los participantes y una encuesta a la ciudadanía, adicional a la revisión bibliográfica general y la reflexión propia. Como conclusión se trató de un movimiento que movió y conmovió a amplios sectores de la población, siendo valorado positivamente.

PALABRAS CLAVE: MÉXICO * MOVIMIENTO SOCIAL * CONSECUENCIAS * INFLUENCIAS

\section{ABSTRACT}

This text focuses on analysing the achievements of Ayotzinapa movement from the social point of view. After the facts in Iguala town in Guerrero State in the year 2014, where 6 people were killed and 43 students disappeared, a movement arose in Mexico. Since the academy is usually study the origins and causes of the movements, but in this case intends to analyze achievements and their consequences. To do this, interviews were conducted with participants and a survey of the citizenship, in addition to the general literature review, and the self-reflection. As conclusion, it was a movement that moved and touched wide sectors of the population, being valued positively.

KEYWORDS: MEXICO * SOCIAL MOVEMENT * CONSEQUENCES * INFLUENCES

1 Se parafrasea una obra de García Márquez, Crónica de una muerte anunciada. Con este juego de palabras no se pretende en modo alguno una sobredeterminación de la movilización. Por supuesto, el origen de una acción colectiva puede ser multicausal, así como es complicado y difícil establecer el complejo de fenómenos que la posibilitan.

* Universidad Autónoma Metropolitana, México.

fpam1721@correo.xoc.uam.mx 
INTRODUCCIÓN

Si la masacre de estudiantes el 2 de octubre de 1968 marcó un parteaguas en la realidad nacional, la desaparición forzada de 43 estudiantes de la Normal Rural de Ayotzinapa el 26 de septiembre de 2014 ha provocado una crisis humanitaria de tal magnitud, que derivó en una crisis de Estado generada por el repudio social que se ha manifestado masivamente a nivel internacional y nacional... (Gómez, 2015, p. 50).

La cita anterior resume la situación de México en otoño de 2014. A estas alturas, tras los años transcurridos desde de la desaparición forzada de los normalistas de Ayotzinapa, todavía se especulan hipótesis sobre lo acontecido realmente esa noche del 26 de setiembre con los jóvenes estudiantes. Los padres y las organizaciones convocaron al movimiento pidiendo que se encuentren a las personas desaparecidas y se castigue a los culpables, no obstante, todavía no aceptan la resolución jurídica y política de las autoridades. Esto refiere a una cuestión emocional y política, a una disputa simbólica que trata de comprender o resignificar la posible muerte de este grupo de estudiantes.

Brevemente, se recuerda que el gobierno apeló a lo que llamó "verdad histórica", consistente en la captura, asesinato e incineración de los normalistas en el basurero de Cocula $y$ el descubrimiento de los restos en el río próximo, según esto, policías municipales de Iguala entregaron al grupo de estudiantes a una organización narcotraficante que los asesinó (El Universal, 2015). Sin embargo, la Comisión Nacional de Derechos Humanos y el Grupo Interdisciplinario de Expertos Independientes señaló una "segunda ruta", según la cual hay pruebas de como un grupo de estos jóvenes fue llevado por policías municipales de Huitzuco, con la intervención por activa o pasiva de la policía federal e incluso del ejército. También se apunta a la acción del narco debido a la no intencional intervención de los estudiantes en sus operaciones al secuestrar un autobús que al parecer transportaba drogas (cNDH, 2016).
Por otra parte, la academia también se pregunta todavía cómo, por qué y de dónde surgió un movimiento de solidaridad tan diverso, amplio y consciente. Aquí se parte de la importancia de saber qué se logró y para qué sirvió en el presente y futuro del país, esto es, la comprensión profunda de este y sus posibilidades de repercusión sociocultural, sin embargo, sigue resonando el por qué, como parte del tradicional funcionamiento de la mente humana en Occidente y de la investigación social en el presente.

Se pondrá el foco en los logros según la mirada social y la opinión pública sobre el movimiento; es decir, la crónica de una movilización anunciada y las consecuencias del movimiento. Anunciada en el sentido que ante la magnitud de la tragedia, heridos, torturados, desaparecidos y muertos a manos de las fuerzas de orden público en complicidad con narcotraficantes, tratándose de estudiantes ¿podría ser de otra manera ${ }^{2}$ ?

El marco de violencia en la región y en el país en los últimos años, aunado a la corrupción e impunidad, a la que se suma la barbarie inocultable ¿Alguien pensaría que no habría protestas entre las y los estudiantes del país? El desencanto $y$ desconfianza en la política y los políticos, así como, en los partidos y el gobierno es inmenso; se habla de crisis política, sin olvidar los problemas sociales y económicos de México, en conjunto con la violencia extrema en algunos lugares y entre ciertos sectores.

2 Sí, seguramente podría ser de otra manera, pero esto sería total especulación. Además, el contexto y la situación son relevantes, ante la violencia reiterada y el hartazgo hacia esta (justo tres años antes surgió el Movimiento por la Paz y la Dignidad en contra de la Violencia). La tragedia y la barbarie de los sucesos en cuestión provocaron un impacto social que originaron un movimiento emocional considerable. Asimismo, los sujetos implicados también importan, el número, la juventud, el ser jóvenes estudiantes, la identificación y proyección en otros jóvenes estudiantes — principales artífices del movimiento-y el despertar de la indignación y la solidaridad social general (Fernández, 2016a y 2017). 
En este contexto, ¿alguien creería que nadie, ni siquiera los jóvenes elevarían la voz?, cuando matan a un hijo o a un alumno ¿alguien puede ni tan solo imaginar que los padres, madres y docentes no se movilizarían?, ¿quién podría pensar o creer que el corazón de la población mexicana está tan congelado? ${ }^{3}$. Ante este caso, es indudable que el movimiento llegó a la parte emocional de la población. Se trata de la muerte, a la cual la vida cotidiana y los medios de comunicación normalizan como parte de los grandes desastres y pequeños sufrimientos humanos. Sin embargo, en esta ocasión fueron 43 secuestrados y desaparecidos forzados, 27 heridos y 6 muertos. Se trata además de estudiantes pobres, rurales, que se preparaban para ser maestros de los pobres de zonas campesinas, pobres entre los pobres, o sabios entre los pobres (Aboites, 2015). En todo caso, los estudiantes más desfavorecidos social $y$ culturalmente hablando.

Las juventudes estudiantiles y universitarias han encabezado luchas y revoluciones más allá de sus demandas gremiales, históricamente han elevado la voz de quienes necesitan, han clamado por la falta de igualdad, libertad $y$ justicia en diferentes momentos y lugares. Además de la coyuntura del país y del Estado, de violencia cruel, injusticia humana, $y$ de una profunda desconfianza a la política, así como hartazgo hacia esta, como se ha reiterado en estas páginas.

Se dice que Ayotzinapa es "la punta del iceberg", "la gota que colmó el vaso", "un parteaguas para el país", entre otras frases. A unos años del suceso, el movimiento está debilitado, pero no por ello los hechos han quedado en el olvido; las nuevas generaciones de infantes $y$ jóvenes coetáneos que conocieron lo ocurrido, lo tendrán en su recuerdo como parte de una memoria colectiva generacional, $y$ quién sabe si algún día se reactivará en el futuro político de México; la semilla germinará y la planta, resultado de esta, algún día florecerá y con posterioridad, fructificará (Fernández, 2016b).

3 Son interrogantes reflexivas ante la dimensión de los hechos en un contexto de violencia, hartazgo y ante una situación que se relaciona al agravio moral y el sentimiento de injusticia total (Moore, 1985).
ESBOZOS DE TEORÍA SOBRE LOS MOVIMIENTOS, SUS LOGROS E INFLUENCIAS SOCIALES ${ }^{4}$

A lo largo de la historia, los movimientos sociales han sido, $y$ siguen siendo, las palancas del cambio social... La mezcla de deterioro de las condiciones materiales de vida y una crisis de legitimidad de los gobernantes y su gestión de los asuntos públicos induce a la gente a tomar sus asuntos en sus manos, participando en acciones colectivas diferentes de los canales institucionales prescritos, para defender sus reivindicaciones $y$, en última instancia, cambiar a los gobernantes e incluso las reglas que conforman su vida (Castells, 2013, p. 209).

Palancas de cambio o movimientos sísmicos y telúricos sociales, los movimientos sociales señalan $y$ expresan la crisis social y política, enfrentándose a la esfera de la política formal, sus actores e instituciones, en los cuales no solo no confían, sino que consideran responsables de los problemas que denuncian $y$ exigen solución. Los desenlaces o consecuencias de los movimientos sociales desde una lectura tradicional es la desmovilización por la obtención de los objetivos — cambios sociales, ideológicos, normativos, reorganizativos, redistributivos - o en su caso, la derrota, la represión, el agotamiento, el conflicto interno o el cierre de oportunidades políticas. Si se aplica una perspectiva dinámica puede hablarse de conflicto político, informalidad, horizontalidad, identidad y potencialidad antisistémica (Ibarra, 2005).

Según Ibarra (2005), los movimientos sociales tienen sus fases, naciente y constitutiva, despegue y desarrollo, pasando a su declive, ya sea por institucionalización, represión o cooptación:

\footnotetext{
4 Se harán unicamente unas aproximaciones teóricas para enmarcar el análisis e interpretación posterior sobre el tema de este estudio.
} 
$\diamond \quad$ Naciente y constitutiva: identidad colectiva, autonomía (rechazo y confrontación con partidos, estado, medios, etc.), globalidad reivindicativa antisistémica, deseo común, consideración de que "se está cometiendo una injusticia en general o una vulneración de sus intereses como grupo" (2005, p. 4), fuerza, entusiasmo, sentirse diferentes, "fuera del mundo de la rutina, de lo establecido. Vivir intensamente una comunidad identitaria, rechazar imposiciones exteriores, utilizar medios de lucha alternativos $y$ construir una visión distinta y global de la realidad es lo diferente. Se elige lo nuevo en los movimientos sociales porque el movimiento necesita para arrancar, constituirse contra, o al menos al margen, del mundo que se combate. Y ese nacimiento fuera del territorio "civilizado", esa voluntad colectiva de misión frente a una realidad exterior degradada, es la que hace que el movimiento se sienta, en ese momento o en esa determinada fase, auténtico y poderoso" (2005, p. 4).

$\diamond \quad$ Despegue y desarrollo: recursos humanos y materiales, individuos especiales o militantes, redes de apoyo humano y material. Estructura y coyuntura de oportunidades políticas. Marcos culturales, identidad colectiva, discurso alternativo, construcción cultural e identitaria. Acciones: convencionales (reuniones, juicios, actos públicos como conferencias, seminarios o mítines, publicaciones, octavillas, recogida de firmas, ruedas de prensa), demostrativas (marchas, cadenas humanas, pancartas, pintas), de confrontación (ocupaciones, obstrucciones tráfico, encadenamientos), ataques menores a la propiedad (hurto y destrucción de bienes), violencia (ataque a propiedades $y$ a personas).

La última fase tras la emergencia y el desarrollo es el final, declive o institucionalización de su expresión visible y material, no de su repercusión afectiva, ideológica e incluso simbólica. Como se señaló con anterioridad, los resultados de la movilización de este movimiento han sido poco trabajados, en el sentido de ver sus logros, más allá de la consecución directa $y$ clara de sus objetivos $y$ demandas, las cuales fueron supuestamente atendidas.

Se dice que es una tarea ardua, de ahí la dificultad de fijar el impacto o la influencia, pues se complejiza el demostrar si los cambios - cuando los hay - son resultado directo de la acción colectiva o de otros factores, sin embargo, se pueden relacionar objetivos de un movimiento con sus logros o incluso, logros en el camino que no habían sido reivindicaciones, aunque la meta última no se haya alcanzado. Desde reformas legislativas hasta transformaciones en prácticas políticas o creación de políticas públicas, hay una amplia gama de respuestas.

En todo caso, aveces las relaciones causa-efecto no son tan directas y claras, lo que parece lógico es como se han ido transformando ideas en la sociedad en su conjunto y se han acumulado experiencias o capital social en las personas implicadas directa e indirectamente. Varios autores afirman que "una vez que los horizontes políticos de las personas se han ensanchado, el cambio es permanente" en el sentido de "experiencia directa en autoorganización, acción colectiva y solidaridad humana" (Graeber, 2014, p. 15). Como lo señala Tarrow (1997):

... no es fácil identificar en un movimiento la causa concreta de un resultado político específico, dado que a las voces de los movimientos hemos de añadir el impacto de los grupos de interés, de los partidos $y$ del ejecutivo y la duración y desgaste del proceso político. Especialmente, en el contexto de los ciclos de protesta, las élites no responden a las exigencias de un movimiento individual, sino a la confrontación generalizada por parte de los disidentes y a la competencia en el seno del sistema político. Las élites median entre las demandas que se les plantean, en busca de soluciones capaces de derrocar a sus enemigos, imponer el control social y satisfacer a sus aliados y seguidores (p. 288). 
Sin embargo, Melucci (1999) recuerda, además de su importante señalamiento de la identidad, la importancia de expresar mensajes y que la sociedad los escuche. Así, los movimientos son eso, mensajeros y mensajes a la vez, más allá de sus logros explícitos está la expresión y la semilla, la cual es sembrada para el periodo de latencia y puede continuar a otra etapa de emergencia de otro movimiento o cambio, incluso en la cultura política.

Un gran número de especialistas apuntan a problemas de orden metodológico y analíticos, pero en este punto, ¿dónde queda la imaginación sociológica? ¿Dónde los enfoques etnográficos y éticos de la antropología? ¿Qué nos puede decir la psicología social o la ciencia política? ¿Cómo no pueden las ciencias sociales esbozar la descripción de posibles logros, aunque sea como prospectiva $y$ escenarios del futuro, sin olvidar la experiencia empírica del presente, especialmente la voz de sus protagonistas o la opinión pública?

Puede darse, directa o indirectamente, una transformación importante de la cultura en general y la cultura política en particular, es la visión del mundo o como dicen algunos, los marcos cognitivos y sociales (Snow y Benford, 2000), dentro del movimiento, militantes y simpatizantes, posiblemente más allá de sus fronteras en función de la difusión, aceptación y solidaridad con su discurso y prácticas. Otros cambios quizás de menor envergadura son pequeños triunfos en cosas concretas, legales $y$ políticas, en la praxis.

Los movimientos en la India con Gandhi o en Estados Unidos con Martin Luther King son considerados un éxito, en estos casos tuvo lugar la institucionalización de los objetivos del movimiento. Por supuesto, no siempre es así, en el sentido de que el declive puede llegar por desgaste, cooptación y represión, como lo señalado anteriormente. No obstante, surge la interrogante de si un aparente fracaso en cuanto a la obtención del objetivo directo es realmente un fracaso en el sentido más allá de lo concreto, pensando en el tiempo de larga duración, las mentalidades, las emocionalidades, las memorias y las consciencias, en el sentido de Wallerstein (1999) para quien fracasos históricos pueden redundar en revoluciones exitosas. Y el papel fundamental de la memoria en la movilización social, así como en la producción misma de memoria colectiva en el transcurso de la lucha (Tilly, 1995).

Para el caso de México, Adame (2013) afirma que los movimientos sociales han tenido "logros y fracasos" pero que sin estos, "el neoliberalismo hubiera sido todavía más avasallador", por ejemplo (p. 131). Alonso (2013) señala que "aunque no logren lo que se proponen $y$ hasta fracasen, su actuación va dejando semillas que en algún momento fructificarán. Los movimientos sociales van construyendo espacios alternativos y generando nuevos valores". Por su parte, Holloway (2012) habla de "como cambiar el mundo sin tomar el poder" y de "grietas al sistema capitalista", concepto que feministas latinoamericanas ya habían usado hace décadas (Sojo, 1985 y Kirkwoord, 1990).

En este sentido, Morin (2011) apunta a las diferentes vías para el viraje social del planeta $y$ su sobrevivencia. Se dejan hasta este punto, las visiones teóricas para dar paso a las miradas perceptuales y prácticas de la ciudadanía en el apartado siguiente, profundizando en el estudio de caso que centra este trabajo.

Para finalizar este recuento de posibles repercusiones, según Martí (2014), hay productos que pueden ser revisados en cuatro ámbitos de la actividad política (sobre los que se volverá más adelante):

$\diamond \quad$ El simbólico: cambios en opiniones, actitudes, valores y conductas; construcción de identidades colectivas; sistema de narraciones que crea nuevos registros culturales de expresión de conflictos y de cómo el statu quo debería ser rediseñado.

$\diamond \quad$ El interactivo: emergencia de nuevos actores sociales y políticos; cambios en la estructura de representación política $y$ alianzas; cambios en la correlación de fuerzas existentes en un ámbito concreto de conflicto.

$\diamond \quad$ El institucional: creación de nuevos procedimientos administrativos, nuevos espacios y mecanismos de negociación inciden e impactan en los espacios que 
regulan y canalizan las conductas de los actores.

$\diamond \quad$ El sustantivo: cambio de políticas gubernamentales, obtención de derechos, nuevas oportunidades de movilización; instrumento de cambio de la realidad.

\section{LOGROS, INFLUENCIAS, RETOS Y CAMBIOS: DATOS E INFORMACIONES PRÁCTICAS}

"Todos los movimientos no tienen la misma historia pero todos nacen y mueren" (Touraine, 2006, p. 277). Lo que sí hacen muchos es ampliar la política "más allá del marco liberal de la distinción entre estado y sociedad civil" (De Sousa, 2001, p. 181). Por otra parte, Tarrow (1997) se pregunta: “Tienen algún impacto, más allá de las efímeras movilizaciones que ocupan los informativos de la noche?....Es real el poder de los movimientos sociales si su impacto está tan mediatizado y es tan efímero?" (p. 18). Para responder a estas interrogantes con el ejemplo de este caso estudiado, es preciso decir que el tiempo tendrá la palabra, pero de momento se tienen algunas respuestas que surgen de la reflexión personal y colectiva, así como del análisis e interpretación de la expresión social popular.

Para ello, se realizó una encuesta sobre el movimiento surgido en torno a la desaparición forzada de los normalistas de Ayotzinapa. Fue aplicada en la ciudad de México en noviembre de $2014^{5}$, a casi dos meses de los hechos que originan el movimiento (muerte de 6 personas $y$ desaparición forzada de 43 estudiantes de la Normal Rural Isidro Burgos de Ayotzinapa, en Iguala, Guerrero). El levantamiento de campo en concreto se realizó en las calles del Centro Histórico. El tamaño de la muestra fue de 600 casos (con una confiabilidad de $95 \%$ y un margen de error de \pm 4) que luego se redujo a 590 al descartarse las personas que dijeron no conocer el movimiento.

Su composición se estableció por cuotas de sexo y edad, la mitad hombres y la otra mitad de mujeres, dividida en tres grupos etarios: 19-29, 30-44, 45 y más; con el objetivo de hacer una comparación según sexo y edad. Es importante mencionar que se trata de un ejercicio no probabilístico, cuyos resultados son representativos de la población encuestada, las inferencias se realizarán sobre la muestra, no obstante, es probable pensar que los resultados señalan tendencias, configurando una suerte de visión general de la opinión pública ciudadana en ese momento.

Sobre el tema de los logros, la encuesta no presenta datos claros en el sentido de una tendencia mayoritaria, la población consultada parece dividida al respecto. Por un lado, 47,8\% afirmó que el movimiento sí tendrá logros, mientras que por otro lado, 44,4\% que no los tendrá, y 7,8\% contestó no saber. Algo más de jóvenes apuntaron el sí y algo más de personas mayores se decantaron por el no (cuadro 1). Fue aplicada en el mes de noviembre, en pleno auge del movimiento, es más, su punto más álgido. Esto se menciona para enmarcar el contexto y coyuntura de las respuestas. Asimismo, se trató de un ejercicio cuyos resultados descriptivos solo son inferencia de la población consultada en la muestra, no del universo total de la población de la ciudad.
5 Como se expone, dicha encuesta tuvo lugar en un momento álgido del movimiento, el cual tuvo una presencia muy activa en las calles de la ciudad de México, con multitud de actividades diversas, de personas en las marchas, acciones en las escuelas,

\footnotetext{
etc. Los meses de octubre, noviembre y diciembre del año 2014 fueron en los cuales el movimiento destacó, por lo tanto, al aplicar la encuesta en noviembre, el movimiento estaba en su plenitud de actividad, visibilidad y expresividad pública.
} 
CUADRO 1

RESPUESTA A LA INTERROGANTE SOBRE

LA EXPECTATIVA DE LOGROS POR PARTE DEL MOVIMIENTO

(PORCENTAJES)

\begin{tabular}{c|ccc|c}
\hline \multirow{2}{*}{ RESPUESTA } & \multirow{2}{*}{$15-29$ AÑOS } & 30-44 AÑOS & 45 AÑOS O MÁS & TOTAL \\
\hline Sí & 18,3 & 13,4 & 16,1 & 47,8 \\
No & 12,9 & 16,3 & 15,3 & 44,4 \\
No sé & 2,4 & 3,4 & 2,0 & 7,8 \\
\hline TOTAL & 33,6 & 33,1 & 33,4 & 100,0 \\
\hline
\end{tabular}

Fuente: Elaboración propia a partir de la Encuesta sobre el Movimiento por Ayotzinapa, ciudad de México, 2014.

Pero ¿a qué se referían o estaban pensando cuando respondían a esta pregunta? Un problema que las encuestas no siempre resuelven. En este caso, el interrogante cuantitativo cerrado era seguido por una pregunta abierta cualitativa, en la cual se invitaba a los que respondieron afirmativamente a expresar los logros considerados. En números absolutos, 282 personas dijeron que sí tendrá logros y 262 dijo que no, además de los 46 que señalaron no saber. En cuanto a los primeros, 21 no supo mencionar alguno (7,4\%). De los testimonios aportados, 261 personas $(92,5 \%)$ respondieron con un logro concreto en una palabra o con una frase expresiva sobre el asunto, que se redujo a una palabra según sus características semánticamente reagrupadas y cuantificadas (cuadro 2).

CUADRO 2

RESUMEN EN FRASES DE LOS LOGROS MENCIONADOS POR LAS PERSONAS ENCUESTADAS (PORCENTAJES)

\begin{tabular}{l|cc}
\multicolumn{1}{c|}{ LOGRO } & \multicolumn{2}{c}{ TOTAL } \\
\hline Castigo a los culpables & 9,5 & 18,3 \\
Justicia & 8,8 & 4,6 \\
\hline Que aparezcan & 2,4 & 2,2 \\
Que se presenten los cuerpos & 1,9 \\
\hline Cambio de gobierno en el sistema de justicia & \\
\hline
\end{tabular}

Fuente: $\quad$ Elaboración propia a partir de la Encuesta sobre el Movimiento por Ayotzinapa, ciudad de México 2014.

Con relación a la cantidad de expresiones vertidas en torno a la percepción y consideración por parte de la ciudadanía interrogada al respecto, la más numerosa fue "castigo a los culpables" con un 9,5\% (25 personas) de menciones directas (corresponde a una solicitud del movimiento), es decir, como frase única en la respuesta y quienes lo mencionaron conjuntamente a otras cuestiones de diversa índole. Por otra parte, el 8,8\% (23 personas) dijeron de forma directa: "justicia” (también solicitud del movimiento), además se reitera de quienes lo expresaron entretejido a una oración de más amplio significado y extensa composición lingüística. Por otra parte, el 2,4\% (15 personas) dijeron de forma directa "que aparezcan" y el $2,2 \%$ (14 personas) "que los encuentren o presenten los cuerpos".

En resumen, estas fueron las cuatro expresiones más notables. La primera y segunda 
se refieren a lo mismo (con algunas disgresiones de significado, ya que la segunda es más amplia que la primera y la incluye). Igual con la tercera y la cuarta (en este caso la primera es amplia y la segunda ya insinúa la muerte), por lo que se ha preferido separarlas y mostrarlas como se recolectaron directamente de la opinión pública.

Por otra parte, el 1,9\% (11 personas) señalaron el cambio de gobierno $y$ de sistema judicial como posible futuro logro en concreto. Se incluye con el objeto de presentar las expresiones de manera más amplia, algunas frases recabadas en el interrogante abierto relacionado al cambio de la sociedad y la política son: "que cambie la forma de pensar de muchos políticos y la sociedad", "que el gobierno cambie de alguna manera". Algunos señalaron la conciencia y el despertar en la misma línea anterior: el "despertar de la conciencia", "ser más conscientes a cerca de la corrupción de nuestro gobierno", "el despertar de la conciencia de la gente dado que ya es internacional", "generar conciencia y empoderar a la ciudadanía", "mayor conciencia de las personas para exigirle al gobierno". También se habló de la importancia de "ser escuchados, que disminuya la violencia respeto a los estudiantes".

Otros testimonios señalaban la responsabilidad del gobierno y situaban el futuro logro en el sentido de "evidenciar la corrupción en todos los niveles de gobierno y que el narcotráfico lo ha permeado todo". También el "explicar lo que pasó" o "saber qué pasó con los estudiantes", sería ya considerado como logro o "que el gobierno escuche $y$ haga caso a los estudiantes". Un grupo se centró en "destitución del presidente" o "quitar a Peña Nieto". Alguien señaló "mejorar el sistema educativo" y "mejorar las normales". Incluso hubo quien consideró logro "que la opinión de la sociedad sea tomada en cuenta" y "que las autoridades hagan su trabajo y se resuelva" o "que las autoridades vean que el pueblo está consciente".

En este ir $y$ venir entre gobierno $y$ ciudadanía que en todo movimiento social acontece, se observa como se pretende expresar, ser escuchados y que además se acuse de recibir las voces de protesta. Un resumen de la concretización de lo que la población consultada considera como logros del movimiento es esclarecer los hechos (aparezcan y presenten los cuerpos) y el establecimiento de justicia (incluido el castigo a los culpables).

Sobre el tema, si bien lo primero no se logró del todo, el movimiento presionó para que se hicieran indagaciones de manera amplia por parte de las autoridades, permitiendo estas la participación de grupos y organismos internacionales en la investigación y de derechos humanos, para el seguimiento del caso ( $\mathrm{CNDH}$, 2016). En cuanto al castigo a los culpables, supuestamente varias personas implicadas intelectual y materialmente en los hechos, están en procesos judiciales: autoridades municipales, policías municipales, grupos delincuenciales locales, sin embargo, otros también señalados como culpables por diversas fuentes, no lo están (El Universal, 2015; cNDH, 2016). El otro logro, aunque numéricamente mucho menor, tiene que ver con la concientización política y social sobre la situación del país, el sistema político y económico, y quién sabe si la vida misma, este último asunto se enlaza a la siguiente técnica de recolección de información de esta investigación.

En los primeros meses del año 2015, cuando el movimiento amplio $y$ activo estaba desmovilizándose, se procedió a la aplicación de entrevistas a 30 jóvenes (entre 18 a 29 años) universitarios de centros públicos y privados de la ciudad de México, quienes habían colaborado o participado de manera directa y comprometida en las actividades del movimiento en la ciudad; además se interrogó a un grupo de jóvenes no universitarios y no participantes en el movimiento (30 jóvenes).

El objetivo principal era conocer el testimonio respecto a la percepción y opinión de los logros y cambios que el movimiento había aportado, tanto a sus consignas y metas concretas, así como, en otras cuestiones referidas a la situación del país desde una mirada más abierta y amplia. Por supuesto, como toda entrevista lo cualitativo se subraya, el significado $y$ la riqueza de los relatos en la voz de participantes y no participantes, personas coetáneas a los hechos y al movimiento. Esta fuente señala 
que según su percepción, los logros son de diversa índole; por ejemplo, la población estudiantil involucrada y las personas participantes en el movimiento afirman que "en cuestión de los desaparecidos no se logró nada porque no se ha sabido qué pasó". En este punto hay quien considera que no ha habido logros "porque no se ha esclarecido todavía el caso".

Sin embargo, también están quienes apuntan como un logro el eco internacional o el apoyo de todo el país: "el crear conciencia en la población sobre la injusticia y el gobierno corrupto" y "la unión solidaria entre los mexicanos". Se ha "visibilizado la situación de violencia, se ha llamado a la conciencia social". Además, hay respuestas más profundas: "considero que la desaparición es una estrategia del gobierno para tocar a los estudiantes $y$ dar a entender que puede meterse con cualquier ciudadano. Sin embargo, este acontecimiento ha servido para abrir los ojos de muchos mexicanos".

Principalmente, el movimiento surgió con el objetivo de encontrar a los compañeros $y$ después se propuso cambiar más cosas del país. Esta última narración de un joven apunta el tránsito del movimiento de un objetivo concreto como es presentación con vida a uno mucho más amplio que significa cambiar y mejorar el funcionamiento de las cosas en México. Proceso y tránsito insinuado en algunos testimonios de la parte cualitativa de la encuesta y que se aprecia en las entrevistas, no obstante, sea un logro en potencia o latente, una intención y deseo sembrado.

En cuanto a la juventud consultada que no participó, su opinión es de que entre sus logros está solo el "ser reconocidos porque no se ha cumplido el objetivo principal que era encontrar a los secuestrados", "los han escuchado, se han movilizado" pero nada más, aunque sí "han traspasado fronteras" y "hay un poco más de presión en el gobierno, las cosas no se hacen tan sencillas como se hacían hace años, esta vez para que la gente lo olvide va a estar más difícil"; esto recuerda a la teoría del reconocimiento (Fraser, 1997; Honneth, 2009). Una joven no participante destacó su composición diversa "en las marchas participan no solo estudiantes, sino trabajadores, amas de casa, padres de familia, entonces tiene un gran impacto en la sociedad mexicana". Sobre esta cuestión se apunta a la complementación de la lucha social $y$ la necesidad de unidad de diferentes reivindicaciones (Mouffe, 1999).

El mayor logro es según los relatos de sus protagonistas "la organización de la gente que hay en el movimiento, hay gente que levantó la voz y ya está en pie de lucha", "la conciencia de la gente hacia el mal gobierno", "muchas personas se han concientizado". De ahí el mayor reto hacia el futuro "con la sociedad, con nosotros mismos porque existen divisiones en el país, no hay un equilibrio... Siento que ya no habrá trabas cuando México se puede entender y organizar bien", "discutir propuestas alternativas, a veces solo criticamos, llegar con propuestas que se puedan articular en un movimiento nacional". Se ha conseguido cierta organización y conciencia, apuntadas como productos positivos del movimiento; el reto es mantenerlo, llegar a entendimientos, cambiar la queja por la propuesta. Una mirada nueva que implica reconocer el propio poder y responsabilidad del ser humano (Marquier, 2012).

Para los consultados no participantes, el logro mayor quizás sea "darnos cuenta, abrir los ojos, de que en cualquier momento pueden tomar decisiones los altos mandos y nos dan en la torre a todos, eso es importante" o "difundir la información ha sido el mayor logro" y "que el caso se ha investigado más de lo que normalmente se acostumbra". Se insiste en que "la gente haga conciencia". Hay quien considera que el mayor reto "ya lo enfrentó, ya enfrentó al gobierno" y otros que "sea un movimiento que no se desvirtúe", además de "mantenerlo vivo porque a estas alturas la gente se ha ido, se ha ido perdiendo el interés", "el desvanecimiento y pérdida de apoyo"6. Esta visión subraya la conciencia y expresión como logros. Como retos está, el superado, de enfrentarse al gobierno y el del que el futuro no se desvirtúe y siga vivo el movimiento. Cuestión esta última que a veces

$6 \quad$ Los testimonios recogidos en entrevista fueron en 2015, cuando el movimiento, sus acciones y su presencia en la ciudad se habían reducido a su mínima expresión. 
se visiona como fracaso, desconociendo que en la vida todo tiene un ciclo, $y$ en los movimientos, también.

En cuanto a su influencia en un cambio hacia una nueva política y según la población participante interrogada, al respecto va en el sentido de que "la sociedad mexicana va creando un poco de conciencia en la gente y quitando complejos para no protestar" o "se crearon nuevas recomendaciones de la cNDH y la corte interamericana". Otra narración señala el "cambio de leyes y reformas" o "al menos retirar alguno que otro corrupto diputado". Son cuestiones a veces no visibles o reconocidas, opacadas por el objetivo principal de un movimiento.

No obstante, en este caso hay que reconocer, como aquí se hace en este testimonio, la apertura del gobierno para la asistencia técnica de grupos de expertos neutrales internacionales, así como, la asesoría de la Comisión Interamericana de Derechos Humanos, entre otros (Gómez, 2015); además de cómo lo dicho con anterioridad, una investigación más amplia y profunda a la usual o el hecho de cesar y procesar a políticos implicados, así como a miembros de las fuerzas de seguridad, que no es poca cosa, en un país en donde en ocasiones reina la impunidad entre la clase política y la institución de seguridad del Estado (Vázquez, 2018).

Sobre la influencia considerada entre los no participantes se señala "creo que sí, aunque la gente dice que no funcionan las marchas, se ha hecho esa presión, $y$ se ha hecho notar, tanto así que llegó a otros países y que esos países piden cuentas a México, porque México no está sabiendo llevar el caso". Un joven afirmó "los normalistas estaban muertos desde el principio, es un movimiento de hartazgo y símbolo de algo mayor", y una chica añadió "cambios sociales, pues la gente tiene que abrir los ojos, tiene que despertar, no tiene que estar a lo que diga el gobierno y a las promesas que nos dan. Pero, por otra parte, los políticos no cambian, siempre van a ser los corruptos de siempre".

Otra muchacha dijo "los partidos no han hecho gran parte por encontrar a los normalistas, sino que casi siempre se ha visto que es por parte de los padres y personas ajenas al gobierno". Este es un punto clave del distanciamiento de partidos políticos y ciudadanía, gobierno y padres, autoridades y movimiento social. No obstante, "en los estudiantes sí impactó, los cambios serán de concientización", "sobre todo en un aspecto social de la gente, en la política creo que no, ahorita sí hubo participación y más unión”.

Quizás "si hubiera más difusión, es que también empieza desde la gente porque todos están como en su mundito, somos muy individualistas, eso hace que no nos importe lo que está pasando, entonces si empezamos a ver la otra parte, a trabajar con ello, $y$ creo que se podría hacer algo". Otra llamada de atención a la necesidad de ver y oír, de pensar y sentir como sociedad, frente al avasallamiento del discurso hegemónico de consumo, miedo y desunión. Se reitera y subraya la frase "en los estudiantes sí impactó y los cambios serán de concientización”, pronunciada por un joven no participante en el movimiento.

Como se observa, el objetivo central de encontrar con vida a los desaparecidos no se logró; sin embargo, hay otra multitud de logros que van desde un tratamiento más acucioso política y jurídicamente del caso, hasta el despertar de la conciencia ciudadana de que las cosas no están bien. Todo ello según jóvenes participantes y no participantes, así como, la ciudadanía consultada al respecto. Sería bueno tener todo lo anterior en mente para quienes piensan y juzgan que fracasó. A veces, la sabiduría popular airea las ortodoxias académicas $y$ ventila las teorías políticas, o las creencias del sentido común que opacan el buen sentido en términos gramscianos (Gramsci, 2001).

\section{MÉXICO NECESITA UN MOVIMIENTO ASÍ}

Una pregunta de la encuesta iba en el sentido de si México necesita un movimiento así, lo cual implica la valoración de mismo según la mirada popular y sobre todo, su evaluación y consideración, directa o indirecta, en cuanto a utilidad. La mayoría de la población de la ciudad de México que fue objeto de consulta respondió mayoritariamente que sí: $73,7 \%$ ante — los más jóvenes_, 23,6\% dice que no - los más mayores-y 2,7\% considera no saber. Por lo que se puede concluir que 
aunque no llega a la mitad de la población la que considera que el movimiento tuvo logros, la mayor parte de la ciudadanía cree que México necesita un movimiento así (cuadro 3), esto es lo reconoce, considera y valora positivamente.

CUADRO 3

¿CREE QUE MÉXICO NECESITA UN MOVIMIENTO COMO ESTE?

\begin{tabular}{c|ccc|c}
\hline RESPUESTA & \multirow{2}{*}{ 15 A 29 AÑOS } & 30 A 44 AÑOS & 45 AÑOS O MÁS & TOTAL \\
\hline Sí & 27,5 & 24,1 & 22,2 & 73,7 \\
No & 5,3 & 8,1 & 10,2 & 23,6 \\
No sé & 0,8 & 0,8 & 1,0 & 2,7 \\
\hline TOTAL & 33,6 & 33,1 & 33,4 & 100,0 \\
\hline
\end{tabular}

Fuente: $\quad$ Encuesta sobre el Movimiento por Ayotzinapa, ciudad de México, 2014.

En este caso no se contó con una interrogante abierta que permitiera el dato cuantitativo ${ }^{7}$. Pero sería posible imaginar que el sí significa o se relaciona con todo lo anteriormente mencionado. Esto es, el reclamo de justicia ante la injusticia, además de la visibilización de la violencia, el despliegue solidario, la unión de amplios sectores sociales, en fin, la conciencia social y política ciudadana. Hugo Aboites (2015) afirma que:

el movimiento en torno a Ayotzinapa - por su naturaleza, integrantes y objetivos...- ha generado un fenómeno sumamente novedoso en el país por su fuerza y amplitud. Es una lucha de los más pobres, de la parte más olvidada de México, pero que logra convertirse en un tema mundial donde intervienen Obama y el papa pasando por gobiernos $y$ organismos internacionales sumamente importantes. A nivel nacional, genera movilizaciones en serie e involucra en torno suyo $-y$ de manera muy notable- a los actores de la educación mexicana, sobre todo estudiantes (p. 89).

$7 \quad$ Por lo que ciertamente, la respuesta queda adscrita al ámbito afirmativo cuantitativo.
$\mathrm{Al}$ inicio de este artículo se apuntaba que no podía ser de otra manera, que se trataba de la crónica de una movilización anunciada en el sentido que la fuerza de ser padre $y$ de buscar a los hijos es inquebrantable, como lo es la responsabilidad de las generaciones adultas sobre los más jóvenes. Si estos mueren o desaparecen ¿quién quedará?, ¿de qué clase de sociedad se trata que desde el poder o con su complacencia extermina a los más jóvenes?

No podría ser de otra manera, porque se trataba sobre todo y como se ha dicho, de jóvenes estudiantes, despertando la empatía o simpatía de otros muchos estudiantes, el sentimiento de injusticia hacia afuera $y$ hacia los otros, $y$ de solidaridad hacia adentro $y$ hacia un nosotros (Tajfel, 1984). La juventud universitaria no podía quedarse indiferente ante este hecho, sin solidarizarse con sus hermanos estudiantes que iban a ser maestros de otros alumnos. Otro asunto que señala este autor es la lección de carácter ético del movimiento (Aboites, 2015):

El movimiento de Ayotzinapa ha podido colocarse en la vanguardia de la transformación social porque es completamente incuestionable desde el punto de vista ético. Un grupo de madres y padres, pobres entre los pobres, protestan a grito airado por la violenta desaparición de sus hijos y con eso cimbran de raíz al Estado 
mexicano, que fue uno de los más perdurables $y$ poderosos... pero Ayotzinapa está poniendo en crisis a ese Estado, precisamente porque su movimiento tiene un carácter de profunda inconstitucionalidad. Pocos — tal vez nadie - tiene estatura moral como para cuestionarlos por su demanda (pp. 90-91).

Prosigue en el mismo sentido: "Que Obama y el papa (y lo más importante, el pueblo de México) no tengan más alternativa que reconocerlos es un logro que muchos de los movimientos no alcanzan, precisamente porque no ha sido posible transmitir un mensaje ético de esa potencia" (Aboites, 2015). Muchos movimientos como este, tienen estatura moral (Touraine, 1990). Es curioso comprobar como en una época donde se habla del vacío, lo efímero, lo líquido o lo riesgoso y la falta de valores morales (Beck, 2002; Bauman, 2007; Lipovetsky, 2009; 2010) aparece la empatía, la solidaridad y la decencia (Rifkin, 2010; Margalit, 2010).

\section{CONCLUSIONES}

Este pueblo no olvida ni olvidará el crimen de Ayotzinapa, así pasen los días $y$ los años...En el alma y la vida del pueblo mexicano esta tragedia seguirá presente, irreductible, dolorosa y viva. Y como rayo que no cesa proseguirá su grito: ¡Vivos se los llevaron, vivos los queremos! (Gilly, 2015).

Retomando lo mencionado en un inicio, respecto a que lo acontecido con los normalistas de Ayotzinapa es una suerte de "un parteaguas para el país" o "la gota que derramó el vaso", o incluso "la punta del iceberg" de toda la violencia que acontece en México, se quisiera concluir sobre ¿qué realmente quiere decir esto? Ante esta pregunta, y como respuesta, rápidamente llegan las palabras de los padres, de los estudiantes; las imágenes de los carteles y las mantas en las marchas populares del movimiento; los sentimientos de sorpresa primero, incredulidad después, junto al dolor, el miedo, el enojo, la indignación, la tristeza, y sobre todo, la solidaridad que invadió al país (Fernández, 2016a y 2016b); el poder de las imágenes y las palabras, la fuerza de las emociones que se difunden de forma pública en el transcurso de los tiempos. Lo que pasó se trató de lo más notable y visible del iceberg, es también lo más insoportable e incontenible que se desborda sin poderlo evitar, todo en el presente; en cuanto al futuro, queda por ver lo del parteaguas del antes, o mejor dicho en este caso, del después.

También se escuchan los ecos de intelectuales que afirman que en otros periodos en Guerrero, algunas matanzas coincidieron con momentos de fundación de proyectos político militares (Hernández, 2015). Por lo que cabe preguntarse también ¿qué pasará hoy al respecto más allá de todo lo expuesto sobre el amplio movimiento social generado? Otros estudiosos especialistas en este Estado recuerdan el ciclo de violencia: reclamo-represión-autogestión, que tiene lugar desde hace tiempo (Illades, 2014).

El último movimiento social estudiantil y juvenil en México fue el \#YoSoy132 en el año 2012 en plena campaña preelectoral, demandando limpieza electoral, voto informado $y$ consciente, entre otras cosas, refrescando la rutina política, aireando la inmovilidad conformista, despertando la supuesta soñoliencia y apatía (Fernández, 2013 y 2015). No se debe olvidar el movimiento de 1968 que en su aparente derrota abrió espacios de participación social, y a pesar del triunfo de las armas del gobierno, este sufrió una derrota moral (Pérez, 2012). Ahora es el \#TodosSomosAyotzinapa, del "yo" — del 132 - al "nosotros" cambia algo más profundo que un pronombre personal en la expresión lingüística, todos es nadie, hay quien dice, $y$ también es la fuerza de la unión en el nosotros, del singular al plural de comunidad, o por lo menos, de colectivo social.

Un nosotros reafirmándose en el "todos", extendiendo su repercusión hasta el infinito, que se identifica y solidariza con el dolor de los padres, hermanos, parejas, maestros, amigos de los normalistas. Un nosotros que se indigna, clama y reclama, grita en las redes y en las calles. Un nosotros que generó la protesta social 
$y$ las manifestaciones de repudio de lo acontecido y reclamo de justicia. Pero, un todos que reconoce la unidad del nosotros, toda vez que excluye, desconoce, niega verbalmente, al ellos. La identidad antagónica mata o desaparece a los otros, al enemigo y al ellos, solo queda $y$ mantiene el todos-nosotros.

Aquí es posible retomar el sentido de Chantal Mouffe - entre otras autoras y autores- de unión de grupos y demandas sociales múltiples: "Un proyecto de democracia radical $y$ plural... requiere la existencia de multiplicidad, de pluralidad $y$ de conflicto, $y$ ve en ellos la razón de ser de la política" (1999, p. 39), en el cual confluyen "una cadena de equivalencias entre las diferentes luchas democráticas, para crear una articulación equivalente entre las demanda de las mujeres, los negros, los trabajadores, los homosexuales y otros" (1999, p. 111).

Pero volviendo a la poética de la protesta, se añade y subraya la ética de la protesta. Pensando y repensando este movimiento, se pudiera definir como una comunidad de lo que viene, no lo que es sino lo que todavía no es (Agamben citado en Méndez, 2015). También se puede aludir a la poética de la protesta en el imaginario de la protesta social, "su carácter anti-estatal, efímero y no institucional". En el caso concreto de Ayotzinapa... lo que permite la cohesión de una comunidad de comunidades, la comunidad que conforma la movilización, es justamente la noción que parece estar fuertemente arraigada en el imaginario de la protesta: la vida.

En este punto, se lleva a cabo un análisis de lo que podría denominarse "la poética de la protesta". Se toma como punto de partida la consigna más fuerte del movimiento: "Vivos se los llevaron, vivos los queremos" (Méndez, 2015, p. 71). Lo anterior en el contexto de la frase singularmente paradójica: "no hay nadie en México que, incluso a pocos días de escuchar la noticia, no haya tenido la certeza —o tomado en consideración la posibilidad- de que esos estudiantes desaparecidos se hallaban ya muertos, acaso, la misma noche de su desaparición" (Méndez, 2015, p. 72).

Touraine (1990) hablaba de los movimientos en torno a las luchas contra viejos patrones culturales, desde la ética y la protesta moral. Melucci (1999) apunta a los movimientos como mensaje y mensajeros, laboratorio cultural, creadores alternativos de la sociedad y el ser. Todo esto se ajusta perfectamente al movimiento estudiado.

En concreto para este caso, a la sorpresa y confusión de la etapa inicial, siguió el enojo y sentimiento de indignación, esto dentro del dolor y tristeza por los acontecimientos, pero a continuación se dio la empatía, solidaridad y reclamo de justicia (Fernández, 2016a). Al sentimiento de injusticia prosiguió la solicitud de justicia. Al agravio social, la acción colectiva (Moore, 1985), la respuesta contra la injusticia (Snow y Benford, 2000), la indignación moral del nosotros, con cierto sentimiento de eficacia, conciencia o posibilidad de cambio (Reis y López, 2007), esto quizás más en el contexto emocional que en la práctica real. Una concatenación de reacciones emocionales y sentimientos morales, enmarcados en valores éticos y sociales, presentes en los movimientos sociales, como lo estuvo en este (Fernández, 2016a).

Tras estos comentarios generales, dos aspectos puntuales se retoman de los objetivos iniciales. En primer lugar, se espera haber dado cabal respuesta en el sentido de la movilización anunciada, ya que como hijos, jóvenes y estudiantes, había posibilidades de que se levantara un movimiento de protesta social de amplio espectro, en el cual, las madres y padres junto a los estudiantes de diferentes niveles educativos $y$ especialmente, universitarios - que hay que reconocer fueron los artífices, movieron y conmovieron, organizaron y dinamizaron al movimiento-salieran a exigir justicia. No sin dejar de ver la indirecta e inintencionada colaboración del errático y desinteresado actuar y desafortunado discurso por parte de las autoridades en el caso - sobre todo tomando en cuenta la magnitud de los hechos y las implicaciones institucionales en el mismo-. Todo ello, por supuesto, tuvo lugar en el contexto expuesto de hartazgo hacia la violencia que se vive en varios lugares del país.

En segundo lugar, en torno a consecuencias y logros desde la mirada, percepción y opinión ciudadana, se pretendió dejarlo claro en este texto. Se centró, según los testimonios 
recabados, en la encuesta y las entrevistas realizadas, en la presión social para una investigación más pronta y expedita, más profunda $y$ seria, con intervención incluida de organismos internacionales; con ceses, detenciones y procesos a algunos responsables policiacos, políticos $y$ delincuenciales; $y$ la solidaridad, organización y conciencia entre los participantes, $y$ por extensión a toda la sociedad, en especial las jóvenes generaciones ${ }^{8}$; no obstante, también se desea realizar algunas puntualizaciones.

Según la información recabada a través de las técnicas y la reflexión realizada de las expresiones recogidas, es posible pensar en posibles cambios de opiniones y actitudes, valores y conductas de la ciudadanía en general, toda vez que la construcción por lo menos provisional de identidades colectivas (Melucci, 1999), así como, narrativas y expresiones de conflictos varias (Martí, 2014).

De hecho, si bien en México hay varios movimientos sociales, este fue inédito en el sentido de espontaneidad, interétnico, interclasista, sumó sectores tradicionales que están en luchas sociales concretas y gentes nunca antes movilizadas y poco afectas a la participación en la protesta social $y$ en movimientos. Su amplitud y diversidad por sí mismas son prueba de su importancia en cuanto a emociones e ideas que confluyeron, todo lo relacionado con lo simbólico y la cultura (Touraine, 1990).

Por otra parte, está la repercusión interactiva en el sentido de emergencia de nuevos actores políticos y sociales, $y$ quién sabe si hubo cambio de correlación de fuerzas existentes en un ámbito concreto del conflicto (Martí, 2004). Hay que tener en cuenta la presencia de diversas formaciones políticas implicadas en el asunto, pues quien gobierna el país es un partido (PRI) y quien gobernaba la ciudad de Iguala $y$ el Estado de Guerrero es otro (PRD) - mismos que a su vez tienen facciones en sus ámbitos de acción y localidades, a veces enfrentadas, como es el caso, y cuyas alianzas además con grupos de narcotraficantes es diferenciada-.

8 Todo ello sin desconocer carencias y desacuerdos y el que todavía no haya respuestas claras sobre lo acontecido, ni justicia sobre los implicados, etc.
En las manifestaciones populares hubo presencia de personas de ambos institutos políticos, quién sabe si por los enfrentamientos internos, los conflictos inter partidarios, o tal vez por la conmoción ética más allá de partidos e ideologías que cimbró a la sociedad. De otro lado, hubo repercusiones institucionales importantes (Martí, 2014), aunque no han sido destacadas por los analistas en su justa medida, la intervención presidencial si bien, tibia o a destiempo, incluso contraproducente, también cuenta. La apertura del gobierno federal para la intervención de actores e instituciones de derechos humanos internacionales es algo a considerar, o el conversar con padres $y$ ofrecer explicaciones públicas, además de la retirada de cargos políticos que se dio; el conocimiento de datos en los medios que en un principio estuvieron ocultos o permanecieron desconocidos, lo cual significa libertad de prensa aunque fuese en ciertos espacios (cNDH, 2016).

Finalmente, en el ámbito sustantivo de cambios de políticas gubernamentales (Martí, 2014), seguramente el descuido y desatención cuando no tendencia a eliminar las normales rurales -escuelas donde se forman a maestros que lo son a su vez en zonas rurales-es posible que se revierta; el cuidado institucional de partidos y autoridades políticas a no repetir impunemente crímenes de esta índole; la amplitud y profundización de derechos ante la respuesta mayoritaria de una sociedad harta $y$ descontenta de la corrupción e impunidad en la política es también otra posibilidad. En fin, perspectivas de cambio actuales y para el porvenir parecen esbozarse varias, ahí el futuro dará una respuesta más certera. Diversos de estos posibles logros aparecen expresados en los testimonios traídos a lo largo de este trabajo, considerados $y$ valorados por las personas consultadas como analistas y reflexivas de su propia realidad política ante las circunstancias que les tocó vivir.

Benjamín Arditi (2012), inspirándose en varios autores señala profética y sabiamente, que toda época piensa o sueña a la siguiente y "sólo podías comenzar a ser libre si actuabas como si ya lo fueras; esto implicaba, tanto 
como fuera posible - y sólo tú sabías qué era posible - desembarazarse del lastre institucional que intentaba convencerte de que nada era realmente posible" (2012, p. 7) y es que "para quienes desean crear una sociedad basada en el principio de la libertad humana, la acción directa es simple y llanamente la insistencia desafiante de actuar como si uno ya fuera libre" (Arditi, 2012, p. 7). Algo así como el cambiar el mundo cambiando (Zivechi, 2007).

Un poco de eso pasó en el movimiento por Ayotzinapa, las personas actuaban como si ya se sintieran libres, con enojo y dolor, con miedo y esperanza, con deseos de solucionar el problema, e incluso de cambiar el planeta, en una exaltación de sentires y reflexiones, ilusiones y certezas, demandas y propuestas (Fernández, 1916a). Unidos por la razón de la emoción y la emoción de la razón, por la emoción y la razón del corazón.

Finalmente, ¿qué queda del movimiento cuando vemos como poco a poco se ha debilitado y está desapareciendo por lo menos en su forma material patente y consolidada, como lo estuvo inicialmente durante los primeros meses? A los logros concretos y prácticos, y las consecuencias de más larga duración, todo ello mencionado, se desea añadir algo más. Los niños y niñas, jóvenes, hombres y mujeres, ancianos, no olvidarán lo ocurrido fácilmente, no solo por la magnitud y crueldad de los sucesos, sino por su repercusión emocional y el movimiento que levantó la voz y tambaleó creencias y sembró consciencias.

El movimiento que tocó el corazón quedará en la memoria colectiva emocional, cultural, social y simbólica. Quizás repercuta en la cultura política de México. Seguro ya ha cuajado la emoción de afecto de las personas particularmente y el sentimiento de justicia en la memoria colectiva. Sobre todo, infantes $y$ jóvenes fueron tocados, movidos y conmovidos, crecerán y madurarán como coetáneos con esas imágenes, voces $y$ memorias dentro de su ser $y$ como parte de su inconsciente colectivo (Fernández, 2016b).

Se concluirá con los testimonios de unos jóvenes de la ciudad de México que aunque dicen no haber participado en el movimiento, parecen tener muy clara la respuesta a los interrogantes políticos, las especulaciones académicas o las dudas de quienes desean profundizar en las causas y sobre todo consecuencias y logros de este movimiento popular:

Creo que sí va a cambiar la sociedad mexicana porque en primera yo soy hijo $y$ tengo padre, ellos se ponen a pensar que yo pude haber sido uno de los desaparecidos. Los papás se ponen a pensar eso. Y yo a lo mejor seré padre en el futuro y no me gustaría que mi hijo estuviera estudiando en algún lado del país y vivir con el miedo de que le pueda pasar algo como lo que acaba de ocurrir. A partir de ahí van a surgir muchas cosas, esperemos que buenas (anónimo, Ciudad de México, 25/02/2014).

Y añade otro:

Más que incidirá el movimiento en la sociedad mexicana, ya está incidiendo. Darnos cuenta de lo que a veces vemos pero lo dejamos pasar por alto. Creo que ya hay un cambio de conciencia de la gente y creo que sí en algún momento pueda cambiar esto para bien del sistema judicial y del sistema político (anónimo, Ciudad de México, 02/03/2014).

Otro más afirma:

Claro, cambia tu manera de ver al gobierno, dejas de verlo como a quien tienes que lamerle las suelas y comienzas a crear conciencia, comienzas a crear tus propias ideas, comienzas a pensar por ti mismo. Al gobierno ya no le será tan fácil robarnos, hace años si la gente desaparecía nadie metía las manos, esta vez con tanto movimiento que se está uniendo creo que en el futuro va a ser más difícil que el gobierno quiera tocar a alguien, la gente va a despertar (anónimo, Ciudad de México, 05/03/2014). 


\section{REFERENCIAS}

Aboites Aguilar, H. (2015). Reformas y Ayotzinapa: percepciones y estrategias en la lucha magisterial (2012-2015). El Cotidiano, 190 (enero-febrero), 83-91. México: Universidad Autónoma Metropolitana, unidad Azcapotzalco.

Adame Cerón, M. A. (2013). Movimientos sociales, políticos, populares y culturales. La disputa por la democracia y el poder en el México neoliberal (1982-2013). México: Itaca.

Alonso, J. (2013) Repensar los movimientos. México: cIEsAs.

Arditi, B. (2012). Las Insurgencias no tienen un plan - ellas son el plan: performativos políticos y mediadores evanescentes. Hemispheric Institute E-Misférica. Recuperado de http://hemisphericinstitute. org/hemi/es/e-misferica-102/ardit

Bauman, Z. (2007). Tiempos líquidos. Vivir en una época de incertidumbre. Barcelona: Tusquets.

Beck, U. (2002). La sociedad del riesgo. Hacia una nueva modernidad. Barcelona: Paidós.

Castells, M. (2013). Redes de indignación y esperanza. Madrid: Alianza Editorial.

Concha Malo, M. (2015). Ayotzinapa: preocupaciones abiertas. El cotidiano, 190 (enero-febrero), 45-49. México: Universidad Autónoma Metropolitana unidad Azcapotzalco.

Chihu Amparán, A. (2000). El análisis cultural de los movimientos sociales. Sociológica, 42, (enero-abril), 209-230. México: Universidad Autónoma Metropolitana unidad Azcapotzalco.

Della Porta, D. y Diani, M. (2011). Los movimientos sociales. Madrid: cIs.

De Sousa Santos, B. (2001). Los nuevos movimientos sociales. osal-clacso, $5,177-188$. Buenos Aires.

El Universal. (2015). Ayotzinapa: Mensaje sobre caso Iguala; La verdad histórica, México. El Universal. Recuperado de http://archivo. eluniversal.com.mx/nacion-mexico/2015/ caso-iguala-murillo-verdad-historica1072311.html
Fernández Poncela, A. M. (2013). Cuando las emociones y la tecnología nos alcancen: \#YoSoy132. Tramas, 40, 177-213.

Fernández Poncela, A. M. (2015). De la red a las calles ¿y de las calles a las conciencias? El movimiento estudiantil \#YoSoy132. Argumentos, 76, 127-157.

Fernández Poncela, A. M. (2016a). Un acercamiento a los sentimientos del y sobre el movimiento por Ayotzinapa (México). RBSE Revista Brasileira de Sociologia da Emocao, 15 (43), 40-62.

Fernández Poncela, A. M. (2016b). Expresiones infantiles: hechos y movimientos, dibujos y sentimientos. 1er Congreso Nacional de Estudios de los Movimientos Sociales, Red de Estudios de los Movimientos Sociales, 18-21 octubre, Rectoría uam, México.

Fernández Poncela, A. M. (2017). Una aproximación a los sentimientos ante la violencia y los movimientos sociales en México. Iberforum, 24, 125-165.

Fraser, N. (1997). Justicia interrupta: reflexioines críticas desde la posición "postsocialista”. Bogotá: Siglo del hombre.

Gómez, M. (2015). Ayotzinapa: de la crisis humanitaria a la crisis de estado. El Cotidiano, 189, 50-59. México: Universidad Autónoma Metropolitana Unidad Azcapotzalco.

Graeber, D. (2014). Somos el 99\% Una historia, una crisis, un movimiento. Madrid: Capitán Swing.

Gilly, A. (27 abril de 2015). Ayotzinapa, el rayo que no cesa. La Jornada. México, p. 10.

Hernández Navarro, L. (2015). Ayotzinapa: el dolor y la esperanza. El Cotidiano, 189, (enero-febrero), 7-17. México: Universidad Autónoma Metropolitana Unidad Azcapotzalco.

Holloway, J. (2012). Agrietar el capitalismo. Buenos Aires: Ediciones Herramienta.

Honneth, A. (2009). Reconocimiento y menosprecio. Sobre la fundamentación normativa de una teoría social. Barcelona: кАТZ/ссСв.

Ibarra, P. (2005). Manual de sociedad civil y movimientos sociales. Madrid: Síntesis. 
Illades, C. (2014). Guerrero: la violencia circular. Nexos. Recuperado de http://www.nexos. com.mx

Kirkwood, J. (1990). Ser política en Chile. Los nudos de la sabiduría feminista. Santiago: Cuarto Propio.

Krauze, E. (10/11/2014). México bárbaro. El País. Recuperado de http://elpais.com

Lipovetsky, G. (2009). La era del vacío. Barcelona: Anagrama.

Lipovetsky, G. (2010). El imperio de lo efímero. Barcelona: Anagrama.

Margalit, A. (2010). La sociedad decente. Barcelona: Paidós.

Martí Puig, S. (2014). Los movimientos sociales. Recuperado de http://campus. usal.es/ dpublico/areacp/materiales/ Losmovimientossociales.pdf

Marquier, A. (2012). El poder d'escollir o el principi de la responsabilitat. Barcelona: Sagarmata.

Mauleón, H. (23/10/2014). El negocio detrás de Iguala. El Universal, 10.

Melucci, A. (1999). Acción colectiva, vida cotidiana y democracia. México: colmex.

Méndez Castro, L. F. (2015). La vida en el imaginario de la resistencia popular por Ayotzinapa: la comunidad en contextos de terrorismo de Estado. Cotidiano, 189, (enero-febrero), 67-72. México: Universidad Autónoma Metropolitana unidad Azcapotzalco.

Moore, B. (1985). La injusticia: bases sociales de la obediencia y la rebelión. México: unam.

Morin, E. (2011). La Vía. Para el futuro de la humanidad. Barcelona: Paidós.

Mouffe, Ch. (1999). El retorno de lo político. Barcelona: Paidós.

Pérez Arce, F. (2012). La luna y el corazón (La cultura rebelde del 68). En El $x x$ mexicano. Lecturas de un siglo, compilado por Carlos San Juan, (pp. 209-229). México: Itaca.

Reis Calvo Hernández, A. y López, J. S. (2007). Los movimientos sociales y lo social en movimiento. Un estudio psicosocial sobre la acción colectiva a través del sector social. Psicología Política, 34, 7-38. Universidad de Valencia.

Rifkin, J. (2010). La civilización empática. La carrera hacia una conciencia global en un mundo en crisis. México: Paidós.

Sojo, A. (1985). Mujer y política. Ensayo sobre el feminismo y el sujeto popular. San José: DEI.

Snow, D. A. y Benford, R. (2000). Framing Processes and Social Movements: An Overview and Assessment. Annual Reviews, 26, 611-639.

Tajfel, H. (1984). Grupos humanos y categorías sociales. Barcelona: Herder.

Tamayo, S. (2015). Crisis política y cultura política. El movimiento por Ayotzinapa. Razón y Palabra, 89, 1-22. Monterrey: теc.

Tarrow, S. (1997). El poder en movimiento. Los movimientos sociales, la acción colectiva y la política. Madrid: Alianza Editorial.

Tilly, Ch. (1995). Las revoluciones europeas: 1492-1992. Barcelona: Crítica.

Touraine, A. (1990). Movimientos sociales hoy. Barcelona: Hacer.

Touraine, A. (2006). Los movimientos sociales. Revista Colombiana de Sociología, 27, 255-278. Bogotá: Universidad Nacional de Colombia.

Zivechi, R. (2007). Autonomía y emancipaciones. América Latina en movimiento. Lima: Universidad Mayor de San Marcos.

Wallerstein, I. (1999). 1968, el gran ensayo. En Movimientos antisistémicos, compilado por en G. Arighi, G; Hopkins, T.K.; Wallerstein, 83-98. Madrid: Akal.

Fecha de ingreso: 05/12/2017 Fecha de aprobación: 19/07/2018 
